\title{
Alliances for Knowledge: MOOCs to Create New Professional Skills in a New Model of University (Positive and Negative Aspects)
}

\author{
http://dx.doi.org/10.3991/ijac.v9i1.5142 \\ Prof. Maria Amata Garito \\ International Telematic University UNINETTUNO, Rome, Italy
}

\begin{abstract}
A generational clash of enormous scope is emerging within our institutions; the criticisms to the university advanced 15 years ago were "waiting ideas": waiting for the new Web and for a new generation of students able to effectively put in question the old model of university. The university in the globalized and the interconnected knowledge society reached a turning point; we are at a crossroads between stagnation and renewal, between atrophy and renaissance. At present, however, there are very interesting facts going on worldwide; in some prestigious universities a new idea of global education is starting from the bottom; many universities are tearing down their ivory towers and are using the Internet, the most powerful platform in history to make their contents available in the Web. Lately, in the United States as well as in Europe, the "Knowledge Alliances" and the MOOCs (Massive Open Online Courses) are emerging. This paper is
\end{abstract} aimed at analyzing the MOOC's phenomenon in the current setting, focusing attention on the role that the University has to play in the knowledge society (section I). In the first part of the work we are going to highlight MOOCs potentials as well as their limits, which are linked, in particular, to their psycho-pedagogic models, to their course assessment systems as well as to the organizational models of the virtual structures aiming at carrying on educational activities based on MOOCs (section II). In section III, it is described the change that the Internet-based technological infrastructure can bring about to the organizational and psycho-pedagogic models of the University of the XXI Century. More specifically, the value resulting from the global networking of the best universities aimed at creating international university consortia aimed at democratizing the access to knowledge is described. The study of concrete case is presented: Consorzio NETTUNO, a consortium born in Italy from the best national and International universities and companies. Some aspects of the educational activity and of the blended (face-to-face and distance) psycho-pedagogic model - adopted by the partnering universities - are highlighted. Then it is described (section IV) the shift to the International Telematic University UNINETTUNO, which implements distance teaching and learning processes in $\mathbf{5}$ languages on the Internet and whose organizational model is analyzed, and that is developed in national and international Technological Poles, set up in several public and private institutions: universities, companies, research and educational centers. The Technological Poles set up in conflict and war areas such as Iraq, Egypt and other countries of the Arab World, play an important role. In section $V$ the results of the most significant research project that allowed to indentify the complex interrelations existing among communication technologies, cognitive processes,

didactic models and educational organizations are described including also the impact that the results of these research projects achieved and are still achieving as it regards the design and realization of the Didactic Cyberspace of the Internet-based Portal of the International Telematic University UNINETTUNO. In the conclusions the paper highlights the fact that, today, thank to the Web, it is possible to make universities with different policies and cultural backgrounds, share study curricula and commonn paths that allow to create new competences as well as new models of integration.

Index Terms-Distance Learning, MOOCs, Knowledge Alliances, e-Learning Platforms.

\section{THE UNIVERSITY IN THE KNOWLEDGE SOCIETY}

All the institutions that are part of the globalised and interconnected knowledge society should find the courage to reinvent themselves through the Internet, the most powerful platform in history. Universities should be at the centre of the interconnected knowledge society; they will have to be the active protagonists of development; they should supply the tools to make people able to interact in the global markets of the Internet while respecting cultural, religious and political differences. The mission of the university has always been that of enhancing and developing mankind and now, regardless of nationality, ethnicity, skin color or gender, the Internet technology can grant everybody access to education and participation in the development of a global economy. In this new setting traditional universities should be able to reinvent themselves and come out of atrophy. Their transformation is no longer a possible option, but it is more than ever an unavoidable imperative. A generational clash of enormous scope is emerging within our institutions; the criticisms to the university advanced between the ' 80 s and an the end of the last Century can be defined as "waiting ideas": waiting for the new Web and for a new generation of students, the digital natives, able to effectively put in question the old model. Many universities are ready to get connected with other environments to make their contents available. Their technological network is working also to create the network of universities and people who can spread and share their own knowledge. Technology is becoming an important linking instrument and is promoting international partnerships even between developed and developing countries, between the university and labor market. 
At present there are very interesting facts going on worldwide: in some prestigious American universities a new idea of global education is starting from the bottom and recently in Europe as well. Many universities are tearing down their ivory towers and are using the Web, to make their contents available to the widest possible audience. The MOOCS (Massive Open Online Courses) make online university courses available, including video lessons, texts and practice work, which is accessible for free to everybody, including the Knowledge Alliances.

This paper aims at briefly presenting:

1. The positive and negative aspects of the MOOCs (Massive Open Online Courses);

2. The technological infrastructure of the University of the XXI Century: the Internet;

3. The universities' new organizational models in the age of the Internet: the Consortia;

4. Two case studies: Consorzio NETTUNO and the International Telematic University UNINETTUNO;

5. The concrete application of the results of research project aimed at identifying new technology-based teaching and learning modes.

The paper ends pointing out the fact that academic alliances among the universities of the various countries of the world can actually meet the needs of an intercultural, globalized and interconnected society.

\section{MOOCS' Positive AND NEGATIVE ASPECTS}

The MOOCs have quickly become very popular in the media worldwide. On the other side of the coin to this success, there are the drop-out rates in the attendance to these courses. The video lessons communication and the assessment models that should certify the acquired skills used in realizing the MOOCs do not seem to be built on robust theoretical bases [1].

There are well-consolidated theoretical models on how to prepare and produce a video lesson. The video lesson uses a visual language to communicate knowledge, based on clearly-established communication rules. The didactic communication model used to realize the video lessons of the International Telematic University UNINETTUNO is the result of several years of research. In 1992 we started with the research project on the "Analysis of Television Models for University Distance Teaching through the Use of Satellites and Computer and Telematic Networks" [2], [3], [4], [5]. and today we keep on conducting research work in this field in order to make methodologies and languages keep up with the technological evolution. In the research work on the video lessons language that I carried out together with my assistants, over 10,000 students who enrolled in Consorzio NETTUNO (the organization from which the UNINETTUNO University took origin) were involved; they were administered some questionnaires aimed at understanding how they developed their learning processes by means of different types of video lessons. The results obtained by processing these questionnaires allowed us to create formats for realizing the video lessons that were very effective in psycho-pedagogical terms. The lecturers, who delivered their courses by means of video lessons, were trained in using a new way of presenting, summarizing and illustrating their knowledge to a virtual student and being able to trigger a critical and thoughtful learning. In order to realize a video lesson each video professor has to work jointly with technicians and experts in visual language; for each hour of video lesson a teacher needs from 20 to 30 hours of preparatory work. The theories on which the video lessons are based are mainly those linked to the mental models of Johnson Laird [6] and to other cognitivist and connectionist theories (Bower, Cirillo [7]; Norman [8]; Gagné, Briggs [9]; Ausubel [10]; Vygotskij [11]) which are linked to the role of the memory, to the functioning of the mind, to comprehension and to learning processes and the theories of Horowitz and Samuels [12] on the related technologies and languages, written language included. In realizing a video lesson the teaching process is divided into several phases: motivation phase, comprehension phase, acquisition and retention phase; recall phase, generalization phase; performance phase and feedback phase [13], [14], [15]. These phases are actually performed through some techniques that turned out to be useful in promoting the learning processes, more specifically: presentation of questions and enquiries; communication of the educational objectives; the presentation of the initial overviews; use of anticipatory or preliminary organizers (Ausubel [10]); particular attention is devoted to integration between oral, written, graphical and video language. Other techniques are connected to the models of use of the teachers' gestures and clothing and to the shooting models that must be adopted by the directors and technicians.

Another pedagogical critical question that was studied as far as the MOOCs are concerned, is the fact that thousands of people enrolled for the MOOCs are left alone to interact on the contents without the guidance of an expert teacher. In the didactic cyberspace on which UNINETTUNO's model relies, on the contrary, the students are not left alone in the Web; they are divided into classes of 20 members and each class is supported by teachers/tutors who are experts in the individual disciplines.

The profile of the teacher is never missing, but it changes role and function. It becomes a Socratic teacher/tutor, teacher-director who designs Internet-based learning settings and guides his own students' knowledge by processing and memorizing distance procedures, by using the art of maieutics. Some MOOCs' assessment systems do not assure the fairness of the results either. There is still no certainty about who really sits in front of a PC. However, we should recognize some positive aspects. The MOOCs started a perfect storm in universities and are allowing many people who are already in the labor market to update their skills and those, who would have been otherwise unable to go to university, to access academic knowledge. Additionally, the analysis of data related to students enrolled in the MOOCs are becoming very valuable for conducting research projects in various fields, including those linked to learning based on the new technologies.

I think that nowadays we need to place the MOOCs into the proper historical and cultural setting; they can be considered as new encyclopedias democratizing the access to knowledge and offering contents that can promote the development of the professional skills required by the global labor market.

This is certainly a very valuable element, however, without a strong supporting system, without a new organizational and pedagogic structure, we cannot think of re- 
placing the University as such, as a place where we cultivate the Life of the Mind.

\section{THE INTERNET: A NEW RENAISSANCE FOR THE UNIVERSITY}

In order to build an infrastructure for the XXI Century higher education we ought to add a technological infrastructure allowing to easily develop a new pedagogic model and a new model of knowledge production and delivery to the universities' physical structures. In this framework, it will be ever more an more important to realize new international alliances aimed at creating a global network of public and private universities sharing their knowledge, pooling their resources and equipments, curricula, laboratories, students' and teachers' internal mobility, while preserving the properties of the individual universities as a value and richness for the network. It is possible to actually create a network of universities by establishing consortia among the universities of different areas of the world and businesses. Consorzia between universities and business may easily allow the development of a global network to provide expertise also to people who are already in the labor market. Being always competitive is crucial for the current knowledge workers, if they want to start and/or progress in their career in a constantly evolving work environment.

It will be the consortia among different universities of the world, which cooperate in the joint production of contents in the Internet-based learning environments, based on a robust organizational and pedagogic model, that will give life to a new model of face-to-face and distance university.

The new university will be a real and virtual place in which, both on the distance and on face-to-face mode, the experience and competence of the teacher is transferred to the students according to continuous interaction models. An interaction among youth and maturity, between experts and non-experts allowing a critical understanding development and, consequently, a transformation into knowledge.

International consortia, supplying the experiences of different universities, allow for quality selection both of the teaching body and of the issues and contents of education, since they can make a choice based on wider and more diversified numbers than can be made by a single university or by local or regional consortia.

Today the best universities, thanks to the Internet, can offer the teaching of the best scientists and scholars of the world in an open and democratic way; they can realize shared study paths and curricula leading to the acknowledgement of titles at international level; they can bring education closer to the business world starting cooperation relationships both curricula design and implementation phases in order to meet the educational needs of a globalised and interconnected labor market.

A university consortium can supply the value of diversity, intended as richness for everybody. A distance university based inside traditional universities allows the traditional universities to regain the role of protagonists in the innovation of products, processes and structures: products flexibility and adaptability, enhancement of student's autonomy, change of the teacher's function and the evolution of the structures that can be used both on a faceto-face and distance basis.
The creation of a higher education global network in which teachers and students from different places of the world participate in the collaborative building of knowledge is not a utopia; these possibilities actually exist and a significant example of this is given by the model of distance university that was developed in Italy with Consorzio NETTUNO - Network per l'Università Ovunque established in 1992, when the Internet did not exist yet. Today, the legacy of Consorzio NETTUNO has been transferred to the International Telematic University UNINETTUNO. Its organizational model used to rely on a consortium among traditional universities and small and big companies. In a very short time we passed from the first three partner universities, as the Politecnico di Torino, the Politecnico di Milano, the University of Naples "Federico II" and such companies as RAI, Telespazio, Telecom Italia, IRI and Confindustria in 1992, to 41 Italian state universities and 38 foreign ones. In 2003 Consorzio NETTUNO, with its 79 partner universities, became the first global distance university in Europe [16].

With Consorzio NETTUNO, the traditional universities were the protagonists of innovation and jointly created new parallel organization models, different from the one of the traditional ones. In the same university two models coexisted: one is still linked to traditional teaching methods, to traditional classrooms such as physical spaces where the face-to-face teaching process took place and in which the teacher was at the center of the process; the other model was based upon the use of new technologies that automatically modified the teaching-learning process, and this required new skills on the teachers' part as well as new physical structures where this process took place. Together with the traditional classrooms we set up Technological Poles, open structures where technologies allowed the implementation of a flexible training process and allow the development of self-learning and of collaborative learning, both face-to-face and at distance. At the beginning of its activity we used satellite television. RAI NETTUNO SAT, broadcasted lectures 24 hours a day, delivered by the best lecturers of the various universities members of the consortium. In 1996, further to the development of the Internet, we realized the first online educational portal in which all training materials were posted. In 1998 the portal was enriched with the first experimental digitized video lessons. Today, in the portal of the International Telematic University UNINETTUNO, there are over sixty thousand hours of digitized video lessons, that are delivered by professors of several universities of the world, in several languages. Video lesson are digitized and indexed by subject and hyper-linked to over six million pages of educational materials of different kinds.

Distance teaching integrated with the institutional functions of traditional universities allowed distance students to be awarded the same study title of the students enrolled in traditional courses. The same teaching body usually divided its time between traditional students and distance students. In order to play their role in this new setting, university teachers carried out all the functions that are envisaged for traditional students, including also others that are typical of distance teaching. Teachers had to learn a new knowledge communication model.

All teaching activities were supervised by teachers belonging not to a single university, but to all partner universities that jointly designed shared curricula, designed and implemented new distance teaching and learning process- 
es. With Consorzio NETTUNO a new pedagogic model was born, a blended model based on a face-to-face and distance bidirectional communication relationship.

The training activities carried on at the Technological Poles, set up in the traditional universities, allow to fully respecting the universities' autonomy that, even though they accepted to deliver distance courses a national level, had the possibility of customizing their own educational offer. The teachers-tutors could post customized contents linked to the various disciplines on the Internet-based portal. These contents allowed to compare knowledge, methodologies, the expertise of different teachers and different universities, not only Italian, but also from other countries and make them a reservoir for all those who could freely access the system. The consortium made available to the partner universities highly-innovative technologies and assured a high qualitative level both of the teaching body and of the educational issues and contents since they were able to rely on the experience of the various partner universities.

Thanks to the satellite television network, RAINETTUNO SAT, which covered and still covers all Europe and all the Mediterranean, African and Asian countries - and to the Internet, in a few years NETTUNO saw its international reputation increase. In fact, it was able to develop its model both in Europe and in the Mediterranean countries, creating the International Telematic University UNINETTUNO. A technological network, as well as a network of people, of intelligences that were able to connect their knowledge within the respect of cultural, political, religious and economic differences.

In the Euro-Mediterranean Area, with the Med Net'U Project, aimed at creating Euro-Mediterranean distance university, 31 universities of 11 Euro-Mediterranean countries (Algeria, Egypt, France, Jordan, Greece, Italy, Lebanon, Morocco, Syria, Tunisia, and Turkey), as well as ministries, vocational training institutions, specialization schools and technological partners such as Eutelsat, joined the consortium [17], [18], [19]. This consortium allowed for the development of shared real and virtual knowledge spaces. These spaces allowed for the creation of the a model of Euro-Mediterranean distance university, born from the cooperation among all traditional universities of the involved countries. Common curricula and psychopedagogic models were developed which allowed to help harmonizing the Euro-Mediterranean educational and training systems. We jointly realized the first Internetbased technological platform, which is unique in the world, in 4 languages (Arabic, English, French and Italian) by which, even today, with the International Telematic University UNINETTUNO, distance teaching and learning processes are jointly run.

These Technological Poles act as innovation incubators from traditional universities and allow to bring about relevant changes in the processes and products linked to the teaching-learning activities. These spaces are all connected to each other and to the head office in Rome through a computer-based network and they were set up also in businesses and municipalities', vocational training centers', public and private facilities' sites and they have always performed educational support functions to distance students. By now anyone having a working Internet access can set up a Technological Poles of his own wherever he lives and even at home.

\section{UNINETTUNO UNIVERSITY TO TRAIN SKILLS FOR THE LABOR WORLD}

The business world, above all, was able to seize the opportunities available by hosting a UNINETTUNO Technological Pole in their premises: many companies set up Technological Poles in their premises to offer their employees the opportunity to continue their university studies and obtain an academic title useful for their career development. This experience, initially started in 1993 with such companies as the Alenia in Naples, the ILVA in Taranto, the IVECO in Turin and the steelworks of Piombino, is very important. In these companies, thanks to the distance teaching model, many mobile workers, after graduating in Computer Engineering, were able to re-enter the fields of the labor world that are linked to technological innovation. With UNINETTUNO the interest in cooperating with the labor world increased a lot and grew at international level. More specifically, the technological pole realized in Rabat, Morocco, in the premises of the Ministry of Vocational Training, allowed UNINETTUNO to make all Moroccan public administration's civil servants achieve computer literacy. With Iraq it realized the EDICT Project - Enterprise Development through Information and Communication Technologies in partnership with the United Nations Industrial Development Organization (UNIDO). The project allowed to realise distance teaching courses for capacity-building linked to the development of new enterprises in the four Governorates of Baghdad, Erbil, Thi-Qar and Basra where they set up four UNINETTUNO Technological Poles.

In these Technological Poles the students had the possibility of studying in the Internet with video lessons and training materials prepared by eminent lecturers coming from Europe, the United States and also from the Arab World, who follow their learning paths also in the Internet. It was a very important experience that was initially carried on with many logistical difficulties, linked to the setting-up of technological poles in war areas, as well as technological ones. These difficulties were linked to the fact that in the Technological Pole of Baghdad and ThiQar it was impossible to make our platform and videoconferencing systems work, since they had to rely on $4 \mathrm{Mbit} / \mathrm{sec}$ and the cost for this kind of connection was 1,725 Us. dollars monthly for each download Mbit (amounting to a total of 6,900 Us dollars monthly), and 2,725 Us dollars monthly for each upload Mbit; very high numbers if compared to the Western World's one and even more so, if we consider the economic possibilities of a country such as Iraq. Once this technological problem was solved, from UNINETTUNO's centre in Rome, in spite of the ongoing conflicts and thanks to our Technological Poles, we keep on training for the skills demanded by the labor market. Other important relations with the business world were established through the ELIS consortium, including 75 big companies of various industrial sectors; jointly with these companies, in a few years, we updated our curricula taking into account the technological evolution and the professional needs of innovative sectors. A very important and significant project was launched in cooperation with Telecom Italia, one of the main telecommunication companies worldwide, including over 55,000 employees, only in Italy. This projects offers Telecom Italia's employees the opportunity of enrolling in UNINETTUNO's degree courses choosing the degree they consider most appropriate to their personal aptitudes, 
interests and dreams. It is the company that bears the costs of the study paths of its employees and this is already leading to a professional and personal new start for many workers.

This project, which falls under the Corporate Social Responsibility activities of Telecom Italia, was called "I care myself: I learn, the Company is with me".

Thanks to this project, a new era in the trade unions negotiations was launched in Italy, where, for the first time, company and trade unions cooperate to offer their employees the opportunity of enhancing their social and cultural status in the workplaces. By developing bilateral agreements and joint projects aimed at staff training, both with the trade unions and the professional associations, today UNINETTUNO has become a strategic partner for governments and private companies both in Italy and the Mediterranean countries. These initiatives are aimed at enhancing the training level of the workers at the support of the professionalism of businesses on global markets. These projects are being developed thanks to the realization of a new portal, "The Skills Portal" which, on the one hand, is aimed at including contents meant to develop the skills required by the new scenarios of the national and international labor market and, on the other hand, is also meant to inform about changes going on in the labor market, about skills and competencies needed to launch new companies in innovative sectors dealing with the application of technologies in the various professional activities.

V. RESEARCH AT INTERNATIONAL TELEMATIC UNIVERSITY UNINETTUNO - FOR A NEW MODEL OF UNIVERSITY

The effectiveness of UNINETTUNO model in the field of vocational training and retraining and in the cooperation with the labor world relies not only on the organizational model being designed and used, but mainly on the distance teaching model included into the UNINETTUNO University's platform which is based on 25 years of research and experimentation work on technologies applied to teaching-learning processes. The commitment of the International Telematic University UNINETTUNO in conducting research work with and about new information technologies is constant. The University itself is a true research laboratory in which hypotheses on the methodologies and languages to be applied and the results achieved by the students in their learning processes are analyzed. These results are continuously assessed by scientists of various fields: cognitive psychologists, linguists, pedagogues, computer science experts assess the effectiveness and efficiency of the proposed psycho-pedagogic models. The outcomes of this research work allowed to identify the complex interrelations existing among communication technologies, cognitive processes, educational models and educational structures. The teaching and learning model implemented in the Didactic Cyberspace of UNINETTUNO's Internet-based platform and its organizational model of the educational structure are the outcome of these research activities.

In UNINETTUNO University the design and realization of the Cyberspace of the educational platform is based on a systemic approach. The applied psychopedagogic theories are mainly linked to socio-cognitive constructivism and allowed to use the Internet to realize constructive and collaborative teaching and learning environments, whose main features are: bidirectional and synchronic and asynchronic interactive communication which allows for an active participation on the student's part in knowledge construction. All the disciplines of the various degree courses include digitized video lessons which are connected through multimedia and hyperlinks to texts, exercises and virtual laboratories in order to promote the transfer of knowledge according to different modes:

- $\quad$ From simple to complex (video lesson and intelligent library);

- $\quad$ From theory to applicative projection (learning by doing in virtual laboratories);

- Guided exercises in searching the World Wide Web (webographies and bibliography);

- From individual study to interactive dialogue between teacher and students and among students in the virtual classrooms, also in UNINETTUNO Island of Knowledge in a 3D environment on the Internet.

The interaction between students and teachers coming from different countries of the world is at the core of the entire educational process and jointly they develop collaborative and constructive learning. Thanks to this psychopedagogic model, the ethics in the use of the Web develop, which allows to recover the value of the presence of a teacher, a presence that, on the contrary, the Web tends to disregard. Actually, a new telematic teacher/tutor's profile is proposed, who, by means of a maieutical art, guides the user/student along his learning path, aiming at teaching him not only how to do things, but also how to be. We witness a radical transformation of the traditional universities' teaching. The Educational structures evolve; they give up the classical isolated system, divided into classes, and replace it with an open and flexible system, capable of updating itself and integrating all knowledge available in the Web.

The richness of cultural exchanges in the educational virtual spaces among individuals belonging to different backgrounds was unforeseeable only a few years ago; today the UNINETTUNO's students come from 140 different countries of the world and this has allowed to create learning communities which have no geographical, cultural, political and religious boundaries. Of course, having realized an educational platform, which is unique in the world, in five languages (Italian, English, French, Arabic and Greek) and ready for delivering educational contents in further languages, made international relations much easier. Even the decision of not relying on the mere "translation" of the contents produced by the lecturers of the Italian universities, but, on the contrary, to involve the best lecturers coming from various universities of the world - giving them the opportunity of preparing contents of the various courses in their own language - greatly helped internationalization.

Students and teachers come from several countries of the world, not only from the European and U.S. universities, but also from the universities of the Arab World countries, such as Algeria, Egypt, Jordan, Morocco, Syria, Tunisia and Turkey. Many university professors coming from these countries, selected by special scientific committees according to their publications' international relevance, delivered and are delivering their courses in the UNINETTUNO's platform. The courses of some faculties, such as engineering, are delivered in Arabic, French, 
English and Italian and, with some Universities of the Arab World, such as the Helwan University in Cairo, where by now many students got a degree, we realized shared curricula which allow to obtain a study title acknowledged both in Europe and in the Arab World. Other shared curricula were realized jointly with the London Business School and other European Universities. This decision was implemented to make linguistic diversity an element of cultural strength in the purpose of building one's own knowledge no longer only according to a local, but also to a global perspective, being confident on the fact that it is easier to solve problems by working with people coming from different cultural backgrounds.

From UNINETTUNO's monitoring centre, it is possible to notice that the interest of learning communities for cooperation is not limited to the educational field, but it is set in a communication framework with wider social and cultural interests. It is through this method that the University engaged in establishing a Euro-Mediterranean Area for Education and Research. The establishment of Euro-Mediterranean Area for Higher Education, deriving from the cooperation among distance universities, traditional universities, vocational training institutions and companies of several European and Mediterranean countries, is essential from a strategic, cultural, political and economic viewpoint.

\section{ACADEMIC Alliances: A GLOBAL STRATEGY FOR BUILDING THE FUTURE}

In the present historical time more than ever, I think it is essential to enhance the cooperation in the fields of university and research. Dialogue between scholars and representatives of the academic world, the harmonization of higher education and research programs, the students and teachers' mobility represent the unavoidable path to be followed to make intercultural dialogue become part of the everyday life of all of us. We all should be aware of the fact that realizing the world Internet-based educational contents and models, together with several universities, we develop the knowledge that helps all citizens to consider cultural, religious and political differences a wealth for humankind and not tools for conflict and war. We cannot remain aloof from the conflicts taking place in several countries of the world since, by now, because of globalization, they will have a stronger and stronger effect on our freedoms.

If universities remain apart, the outcome will be a deep separation from the needs of the society we live in and from the answers that the academic world gives to these needs. This is the reason why I am personally committed to creating, through UNINETTUNO, contents that may be useful to fight against illiteracy in some Arab World countries where these rates are still very high, as they are in Morocco. I designed and realized a course for teaching on television how to read and write Arabic to the Moroccan adult population by using an new pedagogic-didactic model. With this video course, for the first time in an Arab country, they teach Arabic making no reference to the Koran. Further to a careful analysis of the contents carried out by the political authorities of the Kingdom of Morocco the course was accepted and, even today, it is being broadcast in the Moroccan television network, since it actually reduces the illiteracy rate.

Past experience confirms that it is possible to share with the universities belonging to different political and cultur- al backgrounds even common paths of reflection and thinking. Jointly, the interconnected intelligences of the teachers and students of the northern and southern shores of the world will build new knowledge and develop a network of competences and expertise, not based on the imposition of the cultural models of the one or of the other, but on the confrontation among cultures and among educational contents. Jointly, we created a true laboratory for intercultural and inter-linguistic cooperation to develop a new virtual area in which we teach and learn to make young generations become the protagonists of change. UNINETTUNO's teachers and students of the EuroMediterranean area are aware of the fact that this cooperation allows us to create new balances between unity and diversity: the unity of values and of traditions that memory leaves for us and the diversity of cultures and languages. A new model of university that moves under the open skies, with no boundaries, where we build competences for development and lay the foundations on which to build the future together.

\section{REFERENCES}

[1] M.A. Garito (2015), Pedagogical Models for Video Communication in Massive Open Online Courses (MOOCs): A Success Story, in "Global E-Learning", coordinated by the Education and New Technologies Department of UDIMA - Madrid Open University, Madrid.

[2] M.A. Garito (1996), La Televisione nei Processi di Insegnamento-Apprendimento, in M.A. Garito (a c. di), La Multimedialità nell'Insegnamento a Distanza, Garamond, Roma: 181-213.

[3] M.A. Garito (1997), The Role of Television in Teaching and Learning Processes, in Multimedia and Distance Learning for Science and Technology, Garamond, Roma: 239-272.

[4] M.A. Garito (1998), La Télévision dans les Processus d'Enseignement-Apprentissage, in Images and Scientific Education in Europe, European Science and Technology Forum, CNRS, Paris.

[5] M.A. Garito (2007), La Formazione in TV, in «I Quaderni di Telèma - Media Duemila », Roma, 243:14-17.

[6] P.N. Johnson-Laird (1983), Mental Models: Towards a Cognitive Science of Language, Inference, and Consciousness, Harvard University Press, Cambridge (MA).

[7] G.H. Bower, R.K., Cirillo (1985), Cognitive Psychology and Text Processing, in Handbook of Discourse Analysis, Academic Press, New York.

[8] D.A. Norman (1988), The Design of Everyday Things, Basic Books, New York.

[9] R.M. Gagné, L.J. Briggs (1974), Principles of Instructional Design. Holt, Rinehart \&Winston, Oxford.

[10] D. Ausubel (1978), In Defense of Advance Organizers: A Reply to the Critics, in "Review of Educational Research", 48: 251-257. http://dx.doi.org/10.3102/00346543048002251

[11] L. Vygotskij (1978), Mind and Society, Harvard University Press, Cambridge (MA).

[12] R. Horowitz, S.J. Samuels (1987), Comprehending Oral and Written Language: Critical Contrasts for Literacy and Schooling, Academic Press, San Diego (CA).

[13] M.A. Garito., G. Anceschi, M. Botta, (2006), "L’Ambiente dell'Apprendimento" - Web Design e Processi Cognitivi, McGraw-Hill, Milano.

[14] M.A. Garito, (2013), Teaching and Learning on the Internet: A New Model of University, the International Telematic University UNINETTUNO, in CTA - Computer Technology and Application", 4, 9: 476-485.

[15] J. Lowyck (2014), Bridging Learning Theories and TechnologyEnhanced Environment: A Critical Appraisal in Its History, in J.M. Spector et al. (eds.), Handbook of Research on Educational Communications and Technology, Springer Science+Business 
PAPER

Alliances for KNOWledge: MOOCs to Create NeW Professional SKILls in a New Model of University...

Media, New York: 3-20. http://dx.doi.org/10.1007/978-1-46143185-5_1

[16] M. A. Garito (1993), University Distance Education: New Models, New Methods, New Technologies, Flexible Responses in Higher Education, edited by Coen de Vocht, Piet Henderikx, Bruxelles, Stoho, 13-14 December 1993: 117-126.

[17] M.A. Garito (2005), Towards the Euro-Mediterranean Distance University, in "LlinE - Lifelong Learning in Europe - European Adult and Continuing Education Journal" IX, 1: 47-49.

[18] M.A. Garito (2007), Content Sharing between NETTUNO and the Italian and Mediterranean Universities, in European Networking and Learning for the Future. The EuroPACE Approach, Annemie Boonen, Wim Van Petegem (eds.), Garant, Antwerpen-Apeldoom: 185-197.
[19] M.A. Garito (2008), Universities in Dialogue in World without Distance, in Education Landscapes in the $21^{\text {st }}$ Century: Cross Cultural Challenges and Multidisciplinary Perspectives, Cambridge Scholars Publishing: 355-368.

\section{AUTHOR}

Maria Amata Garito is Rector/President of International Telematic University UNINETTUNO, Rome, Italy (e-mail: garito@ uninettuno.it).

Submitted 13 October 2015. Published as resubmitted by the author 23 January 2016. 